\title{
Standardising clinical outcomes measures for adult clinical trials in Fabry Disease: A global Delphi Consensus
}

\author{
D. Moreno-Martinez ${ }^{1}$, P. Aguiar ${ }^{2}$,C. Auray-Blais ${ }^{3}$ M. Beck ${ }^{4}$, D. G Bichet ${ }^{5}$, A. Burlina ${ }^{6}$, D. \\ Cole $^{7}$, P. Elliott ${ }^{8}$, U. Feldt-Rasmussen ${ }^{9}$, S. Feriozzi ${ }^{10}$, J. Fletcher $^{11}$, R. Giugliani ${ }^{12}$, A. \\ Jovanovic $^{13}$, C. Kampmann ${ }^{14}$, M. Langeveld ${ }^{15}$, O. Lidove ${ }^{16}$, A. Linhart ${ }^{17}$, M. Mauer ${ }^{18}$, J. C \\ Moon $^{19}$, A. Muir ${ }^{20}$, A. Nowak ${ }^{21}$, J.P. Oliveira ${ }^{22}$, A. Ortiz ${ }^{23}$, G. Pintos-Morell ${ }^{24}$, \\ $\mathrm{J}$. \\ Politei $^{25}$, P. Rozenfeld ${ }^{26}$, R. Schiffmann ${ }^{27}$, E. Svarstad ${ }^{28}$,A. S Talbot ${ }^{29}$, M. Thomas $^{30}$, C. \\ Tøndel $^{31}$, D. Warnock ${ }^{32}$, M. L West ${ }^{33}$, D. A Hughes ${ }^{1 *}$
}

${ }^{1}$ Lysosomal Storage Disorders Unit, Royal Free Hospital NHS Foundation Trust and University College London, London, UK

${ }^{2}$ Inborn Errors of Metabolism Reference Centre, North Lisbon Hospital Centre, Lisbon, Portugal ${ }^{3}$ Division of Medical Genetics, Department of Pediatrics, Faculty of Medicine and Health Sciences, Université de Sherbrooke, Sherbrooke, Canada

${ }^{4}$ Institute of Human Genetics, University Medical Centre, University of Mainz, Mainz, Germany

${ }^{5}$ Unité de recherche clinique, Centre de recherche et Service de néphrologie, Hôpital du SacréCoeur de Montreal, Montreal, Quebec, Canada

${ }^{6}$ Neurological Unit, St. Bassiano Hospital, Bassano del Grappa, Italy

${ }^{7}$ Department of Medical Biochemistry and Immunology, University Hospital of Wales, Cardiff, Wales, UK

${ }^{8}$ Barts Cardiac Centre, University College London, London, UK

${ }^{9}$ Medical Endocrinology and Metabolism, Rigshospitalet Copenhagen, Denmark 
${ }^{10}$ Division of Nephrology, Belcolle Hospital, Viterbo, Italy

${ }^{11}$ Genetics and Molecular Pathology, SA Pathology Women's and Children's Hospital, North Adelaide, Australia

${ }^{12}$ Medical Genetics Service, HCPA, and Department of Genetics, UFRGS, Porto Alegre, Rio Grande do Sul, Brazil

${ }^{13}$ Department of Endocrinology and Metabolic Medicine, Salford Royal NHS Foundation Trust, Salford, UK

${ }^{14}$ Centre for Paediatric and Adolescent Medicine, University Medical Centre, University of Mainz, Mainz, Germany

${ }^{15}$ Department of Endocrinology and Metabolism, Academic Medical Centre, University of Amsterdam, Amsterdam, The Netherlands

${ }^{16}$ Department of Internal Medicine, Université Paris 7, Hôpital Bichat Claude-Bernard, Paris, France

${ }^{17}$ Department of Cardiovascular Medicine, First Faculty of Medicine, Charles University and General University Hospital, Prague, Czech Republic

${ }^{18}$ Department of Paediatrics, University of Minnesota, Minneapolis, MN, United States

${ }^{19}$ Cardiac Imaging Department, Barts Heart Centre, London, UK

${ }^{20}$ Belfast Heart Centre, Royal Victoria Hospital, Belfast, UK

${ }^{21}$ Department of Endocrinology and Clinical Nutrition, University Hospital Zurich and University of Zurich, Zurich, Switzerland

${ }^{22}$ Service of Medical Genetics, São João University Hospitla Centre, Alameda Hernãni Monteiro, Porto, Portugal

${ }^{23}$ Fundación Jiménez Díaz (IIS-FJD) Área de Patología Cardiovascular, Renal e Hipertensión, Madrid, Spain 
${ }^{24}$ Rare and Metabolic Diseases Unit, Vall Hebron University Hospital, Universitat Autonoma de Barcelona, Barcelona, Spain

${ }^{25}$ Fundation for the Study of Neurometabolic Diseases, FESEN, Argentina

${ }^{26}$ Departamento de Ciencias Biologicas, CONICET, Facultad de Ciencias Exactas, IIFP, Universidad Nacional de La Plata, La Plata, Argentina

${ }^{27}$ Institute of Metabolic Disease, Baylor Research Institute, Dallas, Texas, USA

${ }^{28}$ Department of Clinical Medicine, University of Bergen and Haukeland University Hospital, Bergen, Norway

${ }^{29}$ Department of Nephrology, Royal Melbourne Hospital, Melbourne, Victoria, Australia

${ }^{30}$ Department of Nephrology, Royal Perth Hospital, Perth, Western Australia, Australia

${ }^{31}$ Clinical Trials Unit, Haukeland University Hospital, Bergen, Norway

${ }^{32}$ Division of Nephrology, University of Alabama at Birmingham, Birmingham, Alabama, USA

${ }^{33}$ Medicine, Dalhousie University, Halifax, Nova Scotia, Canada

* Corresponding author: derralynnhughes@nhs.net

Funding: This research did not receive any specific grant from funding agencies in the public, commercial, or not-for-profit sectors 


\begin{abstract}
Background

Recent years have witnessed a considerable increase in clinical trials of new investigational agents for Fabry disease (FD). Several trials investigating different agents are currently in progress; however, lack of standardisation results in challenges to interpretation and comparison. To facilitate the standardisation of investigational programs, we have developed a common framework for future clinical trials in FD.
\end{abstract}

\title{
Methods and findings
}

A broad consensus regarding clinical outcomes and ways to measure them was obtained via the Delphi methodology. 35 FD clinical experts from 4 continents, representing 3389 FD patients, participated in 3 rounds of Delphi procedure. The aim was to reach a consensus regarding clinical trial design, best treatment comparator, clinical outcomes, measurement of those clinical outcomes and inclusion and exclusion criteria. Consensus results of this initiative included: the selection of the adaptative clinical trial as the ideal study design and agalsidase beta as ideal comparator treatment due to its longstanding use in FD. Renal and cardiac outcomes, such as glomerular filtration rate, proteinuria and left ventricular mass index, were prioritised, whereas neurological outcomes including cerebrovascular and white matter lesions were dismissed as a primary or secondary outcome measure. Besides, there was a consensus regarding the importance of patient-related outcomes such as general quality of life, pain, and gastrointestinal symptoms. Also, unity about lysoGb3 and Gb3 tissue deposits as useful surrogate markers of the disease was obtained. The group recognised that cardiac T1 mapping still has potential but requires further development before its widespread introduction in clinical trials. Finally, 
Patients with end-stage renal disease or renal transplant patients should be excluded unless a particular group for them is created inside the clinical trial.

\section{Conclusion}

This consensus will help to shape the future of clinical trials in FD. We note that the FDA has, coincidentally, recently published draft guidelines on clinical trials in FD and welcome this contribution.

\section{Keywords}

Lysosomal Storage Disorders, Fabry Disease, Clinical Trial, Delphi Consensus, Clinical Outcomes, Inherited Metabolic Disorders. 


\section{Introduction}

Fabry disease (FD) is an X-linked lysosomal storage disorder caused by a mutation in the GLA gene which leads to a deficiency of the enzyme alpha-galactosidase A. This impairment leads to accumulation of mainly sphingolipids in cells from different tissues and organs, particularly globotriaosylceramide (Gb3) and globotriaosylsphingosine (lyso-Gb3)[1]. This ultimately results in renal and cardiac dysfunction, potentially early stroke, and white matter lesions in the central nervous system as well as pain, and autonomic disturbance[2].

Two clinical phenotypes have been described: "classical" and "later-onset"[3]. These cannot be predicted exclusively by genotype[4,5]. Classical FD is characterised by a multi-system involvement with early acroparaesthesia, sweating abnormalities and gastrointestinal disturbance, whereas most of the later onset phenotypes may be an attenuated form of the disease, commonly involving a single organ system, usually cardiac or sometimes renal[3].

The incidence of FD has been estimated at 1:50,000, however, new-born screening reveals rates that range from approximately 1:1,250 male live births[6] to around about 1:9000 live births depending on the geographical region, study and definition of $\operatorname{FD}[7-9]$ This may be due to suboptimal awareness, resulting in late diagnosis[10] particularly of later onset and milder forms of the condition[11].

Two different approaches are approved for treatment of FD: Intravenous enzyme replacement therapy (ERT) with Agalsidase alpha (Replagal $\odot$, Takeda) or Agalsidase beta (Fabrazyme $\odot$, Sanofi) and oral therapy with the reversible pharmacological chaperone Migalastat (Galafold(C), Amicus) Several new therapies are in investigation including new intravenous enzymes, oral substrate reduction therapy and gene therapy[12].

Consequently, recent years have witnessed a considerable increase in clinical trial activity of new investigational agents for FD. Several trials investigating different agents are currently in progress. However, lack of standardisation of clinical end points results in challenges to interpretation and comparison and impedes the understanding of benefit of new interventions. 
To facilitate a discussion of the standardisation of investigational programs, we have employed a Delphi consensus process to develop a common framework for clinical trial design in FD. There are three previous studies using Delphi methodology with experts in the field of FD to achieve consensus in various areas. The first one is a 2014 Delphi consensus[13] about best clinical practice in FD which included 15 well-known FD experts and was completed online. It reached consensus in different areas such as diagnosis, decision to start ERT, management of enzyme replacement infusions and adverse effects and follow up/monitoring of patients. The other studies, also published in 2014, tackled the problem of $G L A$ gene variants of unknown significance (VUS) from different perspectives: one proposed an algorithm obtained through Delphi methodology to aid in the diagnosis and management of adults with left ventricular hypertrophy and VUS in the GLA gene another assessed the diagnosis of FD in patients with chronic kidney disease and VUS, , and a third one analysed definitive FD diagnosis in patients who present with non-specific symptoms such as neuronopathic pain and cornea verticillata[14$16]$.

Finally, and coincidentally with the ongoing process of this study, the Food and Drug Administration (FDA) released in August 2019 a draft guidance which provide recommendations to sponsors regarding clinical trial design for approving new drugs and therapies in Fabry Disease[17].

In the current study, 32 FD clinical experts from 4 continents, representing 3389 FD patients, participated in 3 rounds of Delphi procedure. The aim was to reach a consensus regarding clinical trial design, best treatment comparator, clinical outcomes, measurement of those clinical outcomes and, inclusion and exclusion criteria

\section{Methods}

A Delphi methodology was followed to achieve consensus. In the first phase, pre-meeting, an expert in the field and one facilitator (D.A.H. and D.M.M.) reviewed all the clinical outcomes 
hosen in phase 3 and open-label extension clinical trials that had been performed in FD previously.

Clinical outcomes were classified according to organ/system: cardiac, renal, neurologic, gastrointestinal, exercise, quality of life, biomarkers, and others. For each category, the clinical outcome was specified and annotated for type of outcome (primary/secondary outcome), unit of measure, number of studies, months of follow up and statistical significance. After reviewing the literature, internationally known experts were invited to participate in the Delphi Procedure. We collated a list of experts from recent Fabry publications and conference presentations from across the world. We approached them with a personal invitation and explanation by email. In total, there were 46 personal invitations. Of them, 27 were from European countries, 4 from Australia, 4 from South America, 9 from North America and 2 from Asia. The current Delphi panel is formed by the experts who answered the call.

The panel initially evaluated the clinical outcomes listed in the literature review providing free text on possible clinical outcomes, modalities of measurement and possible inclusion and exclusion criteria. Items which were chosen by more than a $10 \%$ of the experts were considered for further review in the second stage. In case no item reached $10 \%$, the threshold would be $5 \%$. In the second survey, participants ranked the different items using a seven-point Likert scale following the guidance previously published[18].

Consensus was defined as:

-Strong consensus/High agreement if $>75 \%$ of the participants chose 5 or more.

-Consensus/ Agreement if $>75 \%$ of the participants chose 4 or more as 3 meant only a $50 \%$ of agreement.

- Disagreement consensus if $>75 \%$ of the participants chose 1 or 2 .

After analysing the results of the second survey, the panel met online to discuss the results and to evaluate if a global consensus was reached or further blinded rounds of survey were required. 


\section{Results}

\subsection{Previous Clinical Trials}

The pre-meeting review of previous clinical trials detected 19 studies. Most of studies were from the early 2000's, with five studies that were still ongoing. 63\% were phase 3 randomized clinical trials studies (RCT) and 37\% were phase 3 RCT plus their phase 4 open-label extensions. The different treatments analysed in the studies were: Agalsidase alpha and beta (73\%) migalastat (11\%) lucerastat (5\%) and PRX-102 (11\%)

A total of 111 clinical outcomes were found. One study followed patients for 65 months.

However, the other studies ranged from 6 to 35 months. 45 clinical outcomes were measured as primary endpoints (41\%) and the rest were secondary. Only kidney endothelium Gb3 deposits, skin endothelium Gb3 deposits and pain at its worst via brief pain inventory (BPI) scale were evaluated in more than one study as a primary endpoint[19-24]. However, secondary outcomes were shared by several studies. Only 31 clinical outcomes reached statistical significance (28\%) and when two completed studies looked at the same outcome, they never agreed on the significance. A summary of the literature review can be found on Error! Reference source not found., with a more detailed analysis of the different studies in the supplementary information 1.

\begin{tabular}{|c|c|c|c|c|c|}
\hline Organ & Clinical Outcomes & $\begin{array}{l}\text { Clinical } \\
\text { Outcomes } \\
\text { Measured } \\
\text { as Primary } \\
\text { Endpoint }\end{array}$ & $\begin{array}{l}\text { Clinical } \\
\text { Outcomes } \\
\text { Measured as } \\
\text { Secondary } \\
\text { Endpoint }\end{array}$ & $\begin{array}{l}\text { Months of } \\
\text { Follow Up }\end{array}$ & $\begin{array}{c}\text { Clinical Outcomes } \\
\text { Which Reached } \\
\text { Statistical } \\
\text { Significance }\end{array}$ \\
\hline Cardiac & $\begin{array}{c}\text { ECG changes } \\
\text { Echocardiography } \\
\text { measures } \\
\text { MRI measures } \\
\text { Blood pressure drop } \\
\text { Clinical events }\end{array}$ & $9(36 \%)$ & $23(92 \%)$ & $6,18,24$, and 35 & $4(16 \%)$ \\
\hline Renal & $\begin{array}{c}\text { Glomerular filtration } \\
\text { rate } \\
\text { Creatinine } \\
\text { Urine analysis } \\
\text { Clinical events } \\
\text { Kidney pathological examination }\end{array}$ & $8(35 \%)$ & $19(82 \%)$ & $6,18,24$, and 35 & $4(17 \%)$ \\
\hline Neurologic & $\begin{array}{c}\text { Clinical events } \\
\text { Brain MRI } \\
\text { Pain } \\
\text { Cerebral blood flow } \\
\text { Hearing loss } \\
\text { Intradermal fibre } \\
\text { density }\end{array}$ & $11(61 \%)$ & $9(50 \%)$ & $\begin{array}{c}5,6,18,24, \text { and } \\
35\end{array}$ & $8(44 \%)$ \\
\hline Gastrointestinal & $\begin{array}{c}\text { Diarrhoea } \\
\text { Pain and other symptomatology } \\
\text { Stool characteristics }\end{array}$ & $1(17 \%)$ & $5(83 \%)$ & 6 & $2(33 \%)$ \\
\hline Exercise & Treadmill stress test & $6(86 \%)$ & $1(14 \%)$ & 18,24 and 35 & $0(0 \%)$ \\
\hline
\end{tabular}




\begin{tabular}{|c|c|c|c|c|c|}
\hline & Pulmonary function & & & & \\
\hline Quality of life & $\begin{array}{c}\text { Questionnaires } \\
\text { Pain medication use }\end{array}$ & $0(0 \%)$ & $4(100 \%)$ & $5,6,18$ and 24 & $1(25 \%)$ \\
\hline Biomarkers & $\begin{array}{l}\text { Plasma Gb3 and } \\
\text { lysoGb3 } \\
\text { Urine Gb3 and } \\
\text { lysoGb3 } \\
\text { Gb3 in tissues } \\
\text { Cystatin-C }\end{array}$ & $7(33 \%)$ & $17(81 \%)$ & $\begin{array}{c}5,6,18,24 \text { and } \\
35\end{array}$ & $8(38 \%)$ \\
\hline Other & $\begin{array}{c}\text { Oxide nitric pathway } \\
\text { Alpha galactosidase activity } \\
\text { Severity score } \\
\text { Body weight } \\
\text { Clinical events } \\
\text { Treatment related outcomes }\end{array}$ & $4(44 \%)$ & $5(56 \%)$ & 6,24 and 35 & $4(44 \%)$ \\
\hline
\end{tabular}

Table 1 Summary of the literature review

In summary:

Cardiac outcomes included ECG changes, echocardiography measures, MRI measures and clinical events. Of all the cardiac clinical outcomes, only left ventricular mass index (LVMI), left ventricular mass, stroke volume, diastolic blood pressure drop and clinical events were evident as end points. LVMI measured via echocardiography was most frequent. All other measures were employed as secondary endpoints. Statistical significance was achieved in the reduction of QRS duration, reduction of LVMI and interventricular septum measured by echocardiography and diminishing LVMI measured by MRI[23, 25, 26].

Renal outcomes consisted of estimated glomerular filtration rate (eGFR) by various methods, measured glomerular filtration rate (mGFR) and creatinine levels. In addition, urine analysis of factors such as microalbuminuria, proteinuria over $24 \mathrm{~h}$, protein/creatinine ratio, albumin/creatinine ratio, variation in proteinuria of more than $33 \%$ and proteinuria defined as more than $300 \mathrm{mg}$ of protein in $24 \mathrm{~h}$. Time to dialysis and kidney transplant were also included. Finally, in this category outcomes relating to renal pathology (other than Gb3 deposits) such as number and state of glomeruli in biopsies and presence or not of tubular pathology were included. eGFR, eGFR slope, mGFR and time to dialysis and transplant were regarded as primary endpoints in different studies. No primary endpoint reached statistical significance. However, some secondary endpoints such an increase in creatinine clearance, reduction of protein/creatinine ratio in urine and an increase of normal glomeruli with a reduction of glomeruli with mesangial widening reached statistical significance in some studies[23, 27]. 
Neurologic outcomes encountered, included clinical neurologic examination, time to event (stroke and transient ischemic attack), cerebral MRI scan analysis, hearing loss improvement and pain analysis. They also included more novel outcomes such as analysis of cerebral blood flow by echography or positron emission tomography (PET) scan and intradermal nerve fibres density. $61 \%$ of neurological outcomes were regarded as primary[20, 23, 27-31] and 44\% reached statistical significance. There was a reduction of average pain measured by BPI item 3 to 6 and pain at its worst measured by BPI, improvement of all the echography items regarding blood flow (pulsatility index, mean velocity, resistance index and peak velocity) improvement of blood flow measured by PET scan and, finally, improvement of hearing loss[23, 28-30].

Gastrointestinal outcomes were taken into consideration in three studies, two still ongoing[20, $22,32]$. The outcomes consisted of clinical symptoms such as diarrhoea, abdominal pain at its worst, general symptoms evaluated by the irritable bowel syndrome scale (IBSS) and other symptoms reported via Likert scale. Furthermore, stool was specifically analysed in the two ongoing studies: One looked at number of days with stools with a Bristol stool scale of 6 or 7 , and the other study looked at stool frequency. All the outcomes were followed for 6 months and only general symptoms reported via Likert scale were considered as a primary endpoint. The endpoints evaluated by the study which had finished, reached statistical significance. They were improvement of diarrhoea and improvement of other symptoms measured via Likert scale[22]. Exercise outcomes consisted of exercise tolerance via treadmill stress test evaluating different parameters and pulmonary function changes. All the exercise outcomes except for the treadmill stress test in two studies, were evaluated as primary endpoints. None of them reached statistical significance[27, 32, 33].

Quality of life was assessed in a general way through SF-36 and EQ-5D-5L questionnaires along with the frequency of pain medication use. Quality of life specifically linked to pain was measured in one study through analysing question 9 of the BPI questionnaire[23]. All quality of life outcomes were evaluated as secondary outcome[21, 26, 32, 34]s. $50 \%$ of the quality of life 
outcomes were being evaluated by studies that still were ongoing. In the other half only the pain related quality of life measured by the question 9 in BPI reached statistical significance.

Plasma biomarkers used as outcomes included Gb3, cystatin C, LysoGb3 in plasma and urine, $\mathrm{Gb} 3$ in different units of measure, $24 \mathrm{~h} \mathrm{Gb3}$ and Gb3 measured in different tissue samples (kidney endothelium, cardiac endothelium, skin endothelium, glomeruli, mesangial space, skin smooth muscle, skin perineurium and finally a 50\% reduction of interstitial capillary accumulated Gb3) The most frequent employed biomarker in plasma was lysoGb3; in urine $24 \mathrm{~h}$ Gb3; and in tissue kidney endothelium Gb3 deposits. While in plasma only Gb3 measured in $\mu \mathrm{g} / \mathrm{mL}$ was evaluated as primary outcome, in tissue all except for podocytes $\mathrm{Gb3}$, mesangial $\mathrm{Gb} 3$ and glomeruli Gb3 were evaluated as primary outcomes. In urine, none of them were evaluated as primary outcome. Statistical significance was reached in plasma measurement in Gb3 measured in $\mathrm{ng} / \mu \mathrm{L}$ and $\mathrm{nmol} / \mathrm{mL}$ as well as lysoGb3 reduction measured in $\mathrm{ng} / \mathrm{mL}$ and $\mathrm{nmol} / \mathrm{L}[22,25,27]$. In urine, a reduction of $\mathrm{Gb} 3$ and $24 \mathrm{~h} \mathrm{Gb3}$ reached statistical significance[21, 22]. Reduction of Gb3 tissue deposits, in cardiac, kidney and skin endothelium achieved statistical significance.

Finally, more difficult to classify outcomes included antidrug IgG antibodies, treatment failure, time to death, time to a composite of clinical events (renal, cardiac, and/or neurologic) body weight change, disease severity score [Mainz severity scale index (MSSI)], alpha galactosidase A activity, and measurement of nitric oxide pathway both at plasma and through skin biopsy. Except for the nitric oxide pathway outcomes, time to death and time to composite clinical events, all the clinical outcomes were evaluated as secondary outcomes. Statistical significance was reached as a decrease of time to the composite clinical events, an increase in body weight and an improvement in both nitric oxide pathway outcomes[23, 27, 35].

\subsection{Delphi survey first round results.}

32 experts answered all phases and were part of the Delphi panel. They came from all around the world and represented all specialities involved in the clinical care of FD patients (Error!

Reference source not found. and Error! Reference source not found.). The mean number of 
FD patients who were being followed by the panel was 113 patients with a mean time working on the field of FD of 16 years.

\begin{tabular}{lrr}
\hline Nationalities & Frequency & Percent \\
\hline Argentina & 2 & 6.25 \\
Australia & 3 & 9.38 \\
Brazil & 1 & 3.13 \\
Canada & 3 & 9.38 \\
Czech Republic & 1 & 3.13 \\
Denmark & 1 & 3.13 \\
France & 1 & 3.13 \\
Germany & 2 & 6.25 \\
Italy & 2 & 6.25 \\
Netherlands & 1 & 3.13 \\
Norway & 2 & 6.25 \\
Portugal & 2 & 6.25 \\
Spain & 2 & 6.25 \\
Switzerland & 1 & 3.13 \\
UK & 5 & 15.63 \\
USA & 3 & 9.38 \\
\hline
\end{tabular}

\section{Table 2 Panel's nationalities}

\begin{tabular}{lrr}
\hline Specialty & Frequency & Percent \\
\hline Biochemistry & 2 & 6.25 \\
Cardiology & 4 & 12.50 \\
Clinical Genetics & 2 & 6.25 \\
Endocrinology & 1 & 3.13 \\
Internal Medicine & 3 & 9.38 \\
Metabolic specialist & 2 & 6.25 \\
Nephrology & 9 & 28.13 \\
Neurology & 9 & 9.38 \\
Pediatrics & 3 & 18.75 \\
\hline
\end{tabular}

Table 3 Panel's medical specialities

Results which passed the designated threshold in phase one are summarised in Error!

Reference source not found. and formed the basis of the voting in phases 2 and 3.

\begin{tabular}{|c|c|c|}
\hline Item & Above Threshold & Below Threshold \\
\hline $\begin{array}{l}\text { Ideal methodology Fabry disease } \\
\text { trial }\end{array}$ & $\begin{array}{l}\text { Adaptative design } \\
\text { Randomized controlled trial }\end{array}$ & $\begin{array}{l}\text { Open label } \\
\text { Registry } \\
\text { Crossover studies }\end{array}$ \\
\hline Ideal treatment comparator & $\begin{array}{l}\text { Agalsidase beta } \\
\text { Agalsidase alfa } \\
\text { Placebo } \\
\text { Best supportive care } \\
\text { Migalastat } \\
\text { ERT (both) }\end{array}$ & \\
\hline How to evaluate renal outcomes & $\begin{array}{l}\text { GFR measured by nuclear medicine or } \\
\text { iohexol } \\
\text { Estimated GFR by CKD-EPI } \\
\text { Proteinuria } 24 \mathrm{~h}\end{array}$ & $\begin{array}{l}\text { Albumin/creatinine ratio } \\
\text { Albuminuria } \\
\text { Renal clinical events (Need for dialysis, renal } \\
\text { transplant) }\end{array}$ \\
\hline $\begin{array}{l}\text { How to evaluate neurologic } \\
\text { outcomes }\end{array}$ & $\begin{array}{l}\text { Stroke and TIA clinical events } \\
\text { White matter lesions }\end{array}$ & $\begin{array}{l}\text { Deafness } \\
\text { Changes in neurological examination }\end{array}$ \\
\hline $\begin{array}{l}\text { How to evaluate quality of life } \\
\text { outcomes }\end{array}$ & $\begin{array}{l}\text { Multidimensional questionnaire } \\
\text { Work compliance } \\
\text { SF-36 }\end{array}$ & EDQ5 \\
\hline How to evaluate cardiac outcomes & $\begin{array}{l}\text { Left ventricular mass index } \\
\text { Cardiac clinical events } \\
\text { T1 mapping }\end{array}$ & $\begin{array}{l}\text { IVS } \\
\text { E/E' } \\
\text { LVEF } \\
\text { ECG changes } \\
\text { Gadolinium late-enhancement } \\
\text { Troponin }\end{array}$ \\
\hline How to evaluate exercise tolerance & $\begin{array}{l}\text { Cardiopulmonary function test } \\
\text { Tolerance questionnaire } \\
\text { Treadmill exercise test } \\
6 \mathrm{MWT}\end{array}$ & \\
\hline $\begin{array}{l}\text { How to evaluate substrate } \\
\text { outcomes }\end{array}$ & $\begin{array}{l}\text { LysoGb3 plasma } \\
\text { LysoGb3 urine }\end{array}$ & Not useful \\
\hline
\end{tabular}




\begin{tabular}{|c|c|c|}
\hline $\begin{array}{l}\text { How to evaluate gastrointestinal } \\
\text { outcomes }\end{array}$ & $\begin{array}{l}\text { Diarrhoea scale } \\
\text { Multidimensional gastrointestinal } \\
\text { scale }\end{array}$ & $\begin{array}{l}\text { Abdominal pain } \\
\text { Number of bowel movements/day } \\
\text { IBSS }\end{array}$ \\
\hline How to evaluate pain outcomes & $\begin{array}{l}\text { Pain scale } \\
\text { BPI }\end{array}$ & $\begin{array}{l}\text { Neurophysiological studies } \\
\text { Number and use of pain medication }\end{array}$ \\
\hline How to evaluate other outcomes & Tissue Gb3 deposits & $\begin{array}{l}\text { Depression } \\
\text { Other biomarkers (TnT, BNP) } \\
\text { Migraine-like headache }\end{array}$ \\
\hline How to evaluate clinical Events & Mainz scale & \\
\hline Fabry disease trial duration & $\begin{array}{l}24 \text { months } \\
36 \text { months } \\
60 \text { months } \\
\end{array}$ & More than 5 years \\
\hline Important inclusion criteria & $\begin{array}{l}\text { Disease-causing mutations } \\
\text { Male gender } \\
\text { Symptomatic Fabry patients } \\
\text { Increased LysoGb3 in plasma } \\
\text { Proteinuria } 24 \mathrm{~h}\end{array}$ & $\begin{array}{l}\text { Decreased AGAL activity } \\
\text { Baseline kidney biopsy with substrate } \\
\text { accumulation } \\
\text { Renal disease } \\
\text { More than } 18 \text { years old } \\
\text { Naïve patients } \\
\text { Classical phenotype }\end{array}$ \\
\hline Important exclusion criteria & $\begin{array}{l}\text { Variant of unknown significance } \\
\text { Non-compliance } \\
\text { Advanced cardiac disease } \\
\text { End-stage renal disease } \\
\text { Stroke } \\
\text { Female gender } \\
\text { Renal transplant }\end{array}$ & $\begin{array}{l}\text { Previous FD treatment } \\
\text { Children }\end{array}$ \\
\hline
\end{tabular}

\subsection{Delphi survey second round results.}

A second survey composed from items that reached the significance threshold in the first survey was sent to the Delphi panel to rate in a Likert Scale from 1 to 7 . Following the consensus definition explained above, consensus results of this initiative are summarised in Error!

Reference source not found. and they included: the selection of the adaptative clinical trial as the ideal study design and agalsidase beta as ideal comparator treatment. Renal and cardiac outcomes, such as glomerular filtration rate, proteinuria and left ventricular mass index, were prioritised as primary outcomes, whereas neurological outcomes including cerebrovascular and white matter lesions were dismissed as a primary or secondary outcome measure. There was also consensus regarding the importance of patient-related outcomes such as general quality of life, pain, and gastrointestinal symptoms and unity regarding lysoGb3 and Gb3 tissue deposits as useful surrogate markers of the disease was obtained. The group recognised that cardiac T1 mapping still has potential but requires further development before its widespread introduction in clinical trials. Finally, regarding inclusion and exclusion criteria, enrolled individuals should not have variants of unknown significance nor advanced disease and it is desirable to be males with symptomatic FD and elevated lysoGb3. 


\begin{tabular}{|c|c|c|}
\hline Item & Consensus & No Consensus \\
\hline $\begin{array}{l}\text { Ideal methodology Fabry } \\
\text { disease trial }\end{array}$ & Adaptative design & Randomized controlled trial \\
\hline Ideal treatment comparator & Agalsidase beta & $\begin{array}{l}\text { Agalsidase alfa } \\
\text { Placebo } \\
\text { Best supportive care } \\
\text { Migalastat } \\
\text { ERT (both) } \\
\end{array}$ \\
\hline $\begin{array}{l}\text { Main primary clinical } \\
\text { outcomes }\end{array}$ & $\begin{array}{l}\text { Cardiac outcomes } \\
\text { Cardiac clinical events } \\
\text { Renal Outcomes } \\
\text { Renal clinical events } \\
\text { Composite clinical events } \\
\text { Quality of life }\end{array}$ & $\begin{array}{l}\text { Substrate } \\
\text { Neurologic outcomes } \\
\text { Neurologic clinical events }\end{array}$ \\
\hline $\begin{array}{l}\text { Main secondary clinical } \\
\text { outcomes }\end{array}$ & $\begin{array}{l}\text { Renal outcomes } \\
\text { Quality of life } \\
\text { Composite clinical events } \\
\text { Cardiac clinical events } \\
\text { Renal clinical events }\end{array}$ & $\begin{array}{l}\text { Cardiac outcomes } \\
\text { Substrate } \\
\text { Neurologic outcomes } \\
\text { Neurologic clinical events }\end{array}$ \\
\hline Exploratory outcomes & $\begin{array}{l}\text { Gastrointestinal outcomes } \\
\text { Pain } \\
\text { Exercise tolerance }\end{array}$ & \\
\hline $\begin{array}{l}\text { How to evaluate renal } \\
\text { outcomes }\end{array}$ & $\begin{array}{l}\text { GFR measured by nuclear } \\
\text { medicine or non-radioactive } \\
\text { product } \\
\text { Estimated GFR by CKD } \\
\text { Proteinuria } 24 \mathrm{~h}\end{array}$ & \\
\hline $\begin{array}{l}\text { How to evaluate neurologic } \\
\text { outcomes }\end{array}$ & Stroke and TIA clinical events & White matter lesions \\
\hline $\begin{array}{l}\text { How to evaluate quality of life } \\
\text { outcomes }\end{array}$ & $\begin{array}{l}\text { Multidimensional } \\
\text { questionnaire }\end{array}$ & $\begin{array}{l}\text { Work compliance } \\
\text { SF-36 }\end{array}$ \\
\hline $\begin{array}{l}\text { How to evaluate cardiac } \\
\text { outcomes }\end{array}$ & $\begin{array}{l}\text { Left ventricular mass index } \\
\text { Cardiac clinical events }\end{array}$ & T1 mapping \\
\hline $\begin{array}{l}\text { How to evaluate exercise } \\
\text { tolerance }\end{array}$ & Cardiopulmonary function test & $\begin{array}{l}\text { Tolerance questionnaire } \\
\text { Treadmill exercise test } \\
6 \mathrm{MWT}\end{array}$ \\
\hline $\begin{array}{l}\text { How to evaluate substrate } \\
\text { outcomes }\end{array}$ & LysoGb3 plasma & LysoGb3 urine \\
\hline $\begin{array}{l}\text { How to evaluate } \\
\text { gastrointestinal outcomes }\end{array}$ & $\begin{array}{l}\text { Diarrhea scale } \\
\text { Multidimensional } \\
\text { gastrointestinal scale }\end{array}$ & \\
\hline $\begin{array}{l}\text { How to evaluate pain } \\
\text { outcomes }\end{array}$ & $\begin{array}{l}\text { Pain scale } \\
\text { BPI }\end{array}$ & \\
\hline $\begin{array}{l}\text { How to evaluate other } \\
\text { outcomes }\end{array}$ & Tissue Gb3 deposits & \\
\hline $\begin{array}{l}\text { How to evaluate clinical } \\
\text { Events }\end{array}$ & & Mainz scale \\
\hline Fabry disease trial duration & $\begin{array}{l}36 \text { months } \\
60 \text { months }\end{array}$ & 24 months \\
\hline Important inclusion criteria & $\begin{array}{l}\text { Disease-causing mutations } \\
\text { Male gender } \\
\text { Symptomatic Fabry patients } \\
\text { Increased LysoGb3 in plasma }\end{array}$ & Proteinuria $24 \mathrm{~h}$ \\
\hline Important exclusion criteria & $\begin{array}{l}\text { Variant of unknown } \\
\text { significance } \\
\text { Non-compliance } \\
\text { Advanced cardiac disease }\end{array}$ & $\begin{array}{l}\text { End-stage renal disease } \\
\text { Stroke } \\
\text { Female gender } \\
\text { Renal transplant } \\
\end{array}$ \\
\hline
\end{tabular}




\subsection{Delphi survey final panel discussion.}

After feedback about the results was given by the facilitator, there was a meeting of the panel. In the meeting, the panel assessed all the items where consensus was met, those which nearly reached consensus and agreed the results. The panel also addressed with detail consensus results which provoked some discussion, such as neurologic complications, the role of female FD patients and VUS in clinical trials

\section{Discussion}

This is the first expert global consensus regarding FD and clinical trials design detailing every aspect of the clinical trial, from the methodology to the clinical outcomes. As with previous consensus on other aspects in FD, it was performed via Delphi methodology.

While the FDA recently released guidance regarding clinical trials, we believe our results expand upon and complement that guidance.

\subsection{Clinical trial design}

Given the rarity of the disease the FDA guidance suggest the use of a single well-controlled trial to approve a new drug for FD to detect a clinically meaningful effect on core clinical aspects of the disease. The definition of a well-controlled trial is given in the document 21 CFR 314.126 which gives recommendation on how to design a good clinical trial taking into consideration an appropriate control group, stratifying at randomization by prognostic factors such as sex and age. The specific clinical trial design is not discussed, stating that any well-controlled clinical trial should "provide sufficient details of study design, conduct and analysis to allow critical evaluation and a determination of whether the characteristics of a well-controlled study are present." However, while no specific clinical trial is recommended, all the recommendations are easier to achieve as a randomized controlled trial (RCT).

The Delphi panel consensus agreed that while RCT have been widely used, there has been increasing understanding that in the field of rare diseases they are difficult to perform[36]. It is 
obvious that rare diseases' clinical trials have fewer potential patients for enrolment but difference in randomization, masking and the use of active comparators has also been found compared to other more common disease areas[37].

Therefore, different clinical trial designs have been increasingly identified to try to solve some of these problems (e.g. adding a run-in phase to the trial). One of them is adaptive clinical trials which allow flexibility through shifting and redesigning the protocol while it is ongoing[38]. While this design is not free of difficulties[39], it may be more relevant to achieve meaningful results in rare diseases than standard RCT. The Delphi panel feel an adaptive design suits better FD due to the complex diversity of clinical outcomes and the small number of patients that are available to participate in clinical trials.

\subsection{Best treatment comparator}

The FDA does not give a recommendation on this matter. In the 21 CFR 314.126 document they state that a comparison of a new drug with a proven treatment is one acceptable strategy to conduct a new clinical trial. The trial can have two groups (new treatment and active treatment) or more than two (for example, new treatment, active treatment and placebo or other treatments or dosages) The Delphi panel reached a consensus specifying one treatment, among others instead of giving general recommendations. The Delphi panel acknowledges that finding an ideal comparator for a potential new FD drug is challenging. However, due to the wider availability and more global experience with Agalsidase beta (Agalsidase alpha is not approved in the United States) and some indications of better biochemical, substrate, and LVMI outcomes, the panel decided to choose only Agalsidase beta as recommended comparator for a FD clinical trial[40-45].

\subsection{Clinical outcomes}

The FDA guidance classifies clinical outcomes according to core clinical disease manifestations. Those core clinical manifestations are renal disease, cardiovascular disease, cerebrovascular disease, gastrointestinal symptoms, and pain. 
Furthermore, the FDA specifies that paediatric patients should have appropriate clinical outcomes to assess disease severity and burden. The same concept applies to late-onset FD.

This Delphi consensus organised clinical outcomes in an alternative way. Clinical outcomes were organised in primary endpoint clinical outcomes, secondary and exploratory outcomes reflecting the importance of different organs involved in FD. It is no surprise to see renal and cardiac outcomes dominate both primary and secondary outcomes. Whilst clinical outcomes that were more subjective such as gastrointestinal involvement or pain were classified as exploratory; the Delphi panel indicated that quality of life must remain an important primary outcome measure.

Conversely, and in distinction from the FDA, neurologic outcomes were dropped from the list. The Delphi panel acknowledged that the pathophysiology of these events is still not fully understood, and this could lead to difficulty interpreting the results of clinical trials. Whilst several efforts have been made to elucidate the mechanisms that trigger neurologic events in FD patients[40], there is no consensus for the incidence of these complications[43, 44, 46] or their long-term implications[47] Furthermore, some studies suggest that stroke and WML progress slowly to be able to see differences in the timespan of a clinical trial[48], which would difficult the measure of the clinical endpoint.

Therefore, the Delphi panel concluded that, until better knowledge of the neurologic involvement in $\mathrm{FD}$, it is reasonable to focus on other outcomes rather than in central nervous manifestations of the disease in primary studies attempting to bring new agents to patient benefit. However central neurological outcomes should be recorded in any clinical trial as a safety endpoint. Further understanding of the pathophysiology and potential for prevention of stroke in FD remains an urgent research need and long-term post marketing follow up of new interventions should further evaluate their effect on stroke.

Finally, while the Delphi panel did not specifically address paediatric outcomes, it understands there might be some special arrangements in paediatric clinical trials, and this could be the subject of a further exercise. 


\subsection{Measurement of cardiac outcomes}

The FDA guidance is more restrictive in this category than in other clinical outcomes. The guidance recommends using only clinical symptoms and exercise capacity as cardiac clinical outcomes indicating that more evidence is needed to support the use of left ventricular mass index or global longitudinal strain as a surrogate marker.

The Delphi panel agreed that in the clinical trial scenario, despite some uncertainty regarding the predictive value of LVMI, given the availability of imaging modalities to monitoring of heart structure and the multiple factor impacting on exercise capacity, left ventricular mass index measured via cardiac MRI should be used to measure cardiac outcomes, alongside cardiac clinical events. It is worth pointing out that the role of native cardiac T1 mapping did not reach consensus. Although native cardiac T1 mapping is an increasingly used technique with promising applications in FD, it has been mainly used for diagnosis[49] and there are still some issues with standardisation of the results which are being addressed[50] and with potential interpretation of changes in response to therapy.

Furthermore, at the panel meeting, experts considered that in the near-future, loop recorder devices could be used to determine whether arrythmias are a useful surogate marker of disease. The ability of loop recorders to detect otherwise undocumented arrythmias may clarify this, specifically for the arrythmias that might occur at an early disease stage[51]. This is currently the subject of active investigation[52].

\subsection{Measurement of renal outcomes}

The guidance from the FDA states that sponsors could use the effect on a specified magnitude of renal function loss either by measured GFR or an accepted estimating equation of GFR. Although they recommend stratifying the loss of renal function according to the various stages of renal disease enrolling patients with different levels of renal function, they do not mention patients already on end-stage renal disease or dialysis They suggest the clinical outcome time to end-stage renal disease or dialysis should be assessed, although this would require a trial of significant duration. 
While GFR decline is an accepted clinical outcome, the FDA guidance states that there is insufficient evidence to support the use of proteinuria as a surrogate endpoint. This decision is based on lack of clear evidence about whether treatment effects on proteinuria can predict treatment effects on other renal outcomes in FD.

Finally, the FDA recommends a thorough optimisation of angiotensin enzyme converter inhibitors and/or angiotensin receptor 2 antagonists in each patient before being enrolled in a clinical trial.

The Delphi panel acknowledged that evaluating renal clinical outcomes is complex and it is one of the clinical outcomes with more variability in its measures across different clinical trials. Consensus was reached in the same items as the FDA guidance, but being more specific: monitoring of GFR evolution via estimated GFR by CKD-EPI, recognising the potential variability of this formula depending on muscularity (which is important in patients experiencing substantial pain) and that it is not suitable for children. A potential alternative of using measured GFR either by nuclear medicine or using non-radioactive substances such as iohexol was recommended. The Delphi panel also agreed on inclusion of all stages of renal function although patients with end-stage renal disease or renal transplant patients should be excluded unless a specific group for them is created inside the clinical trial.

Conversely, the Delphi panel reached consensus about the use of $24 \mathrm{~h}$ proteinuria as a primary clinical outcome. While this was the result from the Delphi procedure, there were some concerns regarding this outcome which were assessed at the final online meeting. First, the panel recommends the measure of both total protein and albumin. Albuminuria is considered an early and sensitive surrogate marker of renal involvement, although renal changes have been witnessed without increased urine albumin and there can be differences between males and females[53]. Secondly, some experts considered collecting urine for a $24 \mathrm{~h}$ period practically complex, highly variable, and unpopular among patients. In addition, the volume of urine might interfere with the results. 
A solution put forward was the use of protein/creatinine and albumin/creatinine ratio of the first void urine in the morning, or a median of three separated void urine collections[54]. However, the fact that protein/creatinine ratio did not achieve consensus might indicate some specialists feel the ratio to be more complex to use than the raw proteinuria or albuminuria number, and its use could be less common outside nephrology clinics.

Nevertheless, the Delphi panel considered this an inexpensive, easy to measure outcome that while it is true there are limitations for albuminuria and proteinuria as a surrogate marker endpoint in a clinical trial, they are the cornerstone of treatment of most, if not all, proteinuric nephropathies[55] and therefore should be measured in FD clinical trials, and patients with high or progressive proteinuria should not be excluded.

Finally, the Delphi panel agreed on stabilising and monitoring angiotensin-converting enzyme inhibitors and other drugs used for renal and cardiac dysfunction that can have an impact on renal outcomes prior to the enrolment of the patient in the clinical trial

\subsection{Measurement of gastrointestinal and pain outcomes}

The FDA classifies pain and gastrointestinal symptoms as neuropathic pain due to their physiopathology. Nevertheless, it states that they might be enough to establish drug effectiveness if an improvement in abdominal or general pain, diarrhoea or constipation is observed through well-defined and reliable instruments[56].

While effort has been exerted to unveil the physiopathology of pain and gastrointestinal manifestations in $\mathrm{FD}[57]$, their subjectivity remains a challenge. Besides, some common tools to evaluate pain in FD pains, such as BPI does not record appropriately FD pain crisis. Hence, although the Delphi panel did not wish to undervalue the effect of these manifestations, on patients with Fabry disease[58,59] their effects were felt to impact on overall quality of life which as such must remain as a primary clinical outcome, evaluating gastrointestinal and pain outcomes as exploratory outcomes. Finally, when measuring pain as a clinical outcome in a clinical trial, the panel would recommend optimising and standardising analgesic medication of patients prior to inclusion in any trial. 


\subsection{Gb3 in tissue and LysoGb3 as a substrate biomarker}

Gb3, can be detected in histological samples from several organs and is a direct detection of damage and active disease. Widely used for diagnosis, due to its direct relationship with organ damage the FDA recognises its use when looking at the reduction in renal interstitial capillaries. It would act as a surrogate marker that can support an accelerated approval of a drug.

On the other hand, plasma lysoGb3 has gained some acceptance as a substrate related biomarker which may have greater significance than its obvious pharmacodynamic interpretation[60]. Although most patient's plasma lysoGb3 diminishes after treatment and a higher plasma lysoGb3 is correlated with a severe phenotype[61] the long-term corollaries of its reduction are as yet unproven. Further studies are warranted regarding this issue.

LysoGb3 analogues may also be detected in urine[62]. However, these are not yet widely available. Therefore, the Delphi panel agreed on monitoring plasma lysoGb3 levels during the clinical trial duration but did not agree a consensus on the measurement of urinary lysoGb3 or other analogues. The panel recommends $\mathrm{Gb} 3$ detection in tissue as a reliable surrogate marker of the disease.

\subsection{Fabry Disease trial duration}

The FDA does not state a specific duration of a FD clinical trial. It recommends that if the clinical trial's aim is to observe a reduction in disease's progression, it should allow enough time to observe disease progression in the control group. For example, in case of renal outcomes, it should be 24 months.

The Delphi panel acknowledges that FD is a disease with a slow but steady rate of progression. While it can cause vital complications, usually they are developed over many years[3]. Therefore, to be able to see clinical differences, clinical trials should ideally last long enough to witness these differences.

In this sense, the panel recognises that some commonly used markers of the disease, such as cardiac clinical events, might have a too slow event rate to be practical for pre-authorisation 
clinical trials and potentially impede the development of a beneficial intervention. There is therefore evidently a need to explore new and existing biomarkers of disease which responds within a practical timeframe and therein to understand their long-term relationships with clinical events.

Meanwhile, the Delphi panel agreed on a 36 and 60-months duration for the initial study with additional open-label data collection.

\subsection{Inclusion and exclusion criteria - Chronic renal disease and transplant.}

The FDA guidance draft specifies that confirmed FD patients through biochemical (plasma and leukocytes alpha galactosidase A activity) and genetic testing of GLA gene are eligible to enrol in a clinical trial. Both females and males should be considered for enrolment. In addition, it states that children should be considered too.

Regarding genotype, the FDA considers that in the case of variants of unknown significance if there is biochemical or histopathological evidence of FD they can be accepted to participate in a clinical trial.

Similarly, the Delphi panel reached a consensus on inclusion criteria which demonstrate that the patient has FD with ongoing storage and organ effects, as it can be seen in table 4. Assuming all the candidates entering the study have a confirmation of FD following published recommendations[25], the panel felt that more specific inclusion criteria should be taken into consideration including male gender.

The selection of male gender as inclusion criteria was addressed at the online meeting. This decision was mainly driven by the need to evidence clear changes in the affected patients. The more severe phenotype of the disease tends to be more frequent in males and therefore, improvement is more easily observed and rapidly evaluated in these patients. However, new drugs being developed as treatment of Fabry disease should be suitable for both genders, a broad spectrum of disease stages and different genotypes. 
Consequently, the panel agreed that a stepwise clinical trial should be recommended, accordingly the adaptive clinical trial design. In this design, the first step would be to test new drugs in males with classical FD. Once benefit is observed, then females and, afterwards patients with late-onset phenotypes will be included. Therefore, the panel wants to highlight female gender is not an exclusion criteria, but given the inter-patient variability in females, a significant clinical effect is more likely to be detected in males, hence, a tiered approach would be desirable.

Other inclusion criteria where consensus was agreed were recognised disease-causing mutations, symptomatic patients (ongoing organ damage) and increased lysoGb3 in plasma.

Unlike the FDA, the panel reached consensus on exclusion of VUS since the aetiology of clinical findings were not clear in such patients. Other exclusion criteria where consensus was met were advanced cardiac disease (defined by the extension of fibrosis and left ventricular hypertrophy specially with the presence of concomitant heart failure, arrhythmias or myocardial ischemia) due to the difficulty in reversing fibrosis and advanced myocardial remodelling, and non-compliance patients. The panel recommended that patients with end-stage renal disease or transplant should participate in a designated group and should not be excluded.

\section{Conclusions}

This Delphi driven consensus aimed to set a framework for future clinical trials in adult FD thought standardisation of different elements: clinical trial design, treatment comparator, clinical outcomes endpoints, duration, inclusion, and exclusion criteria.

Following Delphi methodology, the panel of experts reached a consensus on all the areas. Main recommendation of this initiative are:

1. The selection of the adaptive clinical trial as the ideal study design

2. Agalsidase beta as the ideal comparator treatment. 
3. Renal and cardiac outcomes should be prioritised as primary or secondary outcomes, whereas neurological outcomes, including cerebrovascular and WML, should be considered in longer phase 4 studies.

4. Patient-related outcomes such as pain, gastrointestinal symptoms and, especially quality of life, are vital and consequently, quality of life outcomes should be included as a primary endpoint.

5. The most appropriate measure of renal outcomes are evolution of GFR (CKD-EPI or measured), 24h proteinuria and albuminuria and protein or albumin/creatinine ratios.

6. The most appropriate measure of cardiac outcomes are LVMI measured by MRI and clinical events. T1 mapping lacks sufficient standardisation and prognostic value to be currently recommended. It is recognised that loop recorder devices might be a future asset to any FD clinical trial because their ability to register previously undetected arrhythmia events, specially some that might happen at an early stage.

7. Plasma lysoGb3 and $\mathrm{Gb} 3$ tissue deposits are useful surrogate markers of the disease which may shorten the duration of clinical trials. However, further work is required to fully understand the relation of biomarkers and surrogates to clinical outcomes.

8. Duration of at least 36 to 60 months is recommended due to the slow rate of progression of the disease. An additional open-label phase should follow.

9. The demonstration of FD with ongoing organ damage is the foundation of clinical trial inclusion criteria. These are a pathogenic genetic variant, increased lysoGb3 in plasma, evidence of clinical disease and male gender. A stepwise adaptative approach should include the subsequent inclusion of females and patients with late onset disease in any study where effect is demonstrated in the first round with classical males.

10. Exclusion criteria include variants of unknown significance, advanced cardiac disease and non-compliance. 
11. End-stage renal disease or renal transplant is not considered an exclusion criterion.

However, these patients should be included in a specific study group.

This consensus may allow more rapid clinical trial development and implementation to understand therapeutic effects of new agents in FD and allow comparability and reduction of unwarranted variation in clinical study design. Finally, further similar work is required considering clinical trial design in children and evaluation of new organ-specific measurement techniques as they become available.

\section{References}

1. Ferraz MJ, Marques ARA, Appelman MD, Verhoek M, Strijland A, Mirzaian M, et al. Lysosomal glycosphingolipid catabolism by acid ceramidase: Formation of glycosphingoid bases during deficiency of glycosidases. FEBS Letters. 2016;590(6):716-25. doi: 10.1002/18733468.12104.

2. Germain DP. Fabry disease: Orphanet J Rare Dis; 2010 [cited 5].

3. Mehta A, Hughes DA. Fabry Disease. In: Adam MP, Ardinger HH, Pagon RA, Wallace SE, Bean LJ, Stephens K, et al., editors. GeneReviews((R)). Seattle (WA)1993.

4. Rodríguez-Marí A, Coll MJ, Chabás A. Molecular analysis in Fabry disease in Spain: Fifteen novel GLA mutations and identification of a homozygous female. Human Mutation. 2003;22(3):258-. doi: 10.1002/humu.9172.

5. Germain DP, Poenaru L. Fabry disease: Identification of novel alpha-galactosidase A mutations and molecular carrier detection by use of fluorescent chemical cleavage of mismatches. Biochemical and Biophysical Research Communications. 1999;257(3):708-13. doi: 10.1006/bbrc.1999.0310.

6. Hwu WL, Chien YH, Lee NC, Chiang SC, Dobrovolny R, Huang AC, et al. Newborn screening for fabry disease in taiwan reveals a high incidence of the later-onset GLA mutation c.936+919G>A (IVS4+919G>A). Human Mutation. 2009;30(10):1397-405. doi: 10.1002/humu.21074.

7. Brouns R, Thijs V, Eyskens F, Van Den Broeck M, Belachew S, Van Broeckhoven C, et al. Belgian fabry study: Prevalence of fabry disease in a cohort of 1000 young patients with cerebrovascular disease. Stroke. 2010;41(5):863-8. doi: 10.1161/STROKEAHA.110.579409. 8. Burlina AB, Polo G, Salviati L, Duro G, Zizzo C, Dardis A, et al. Newborn screening for lysosomal storage disorders by tandem mass spectrometry in North East Italy. Journal of Inherited Metabolic Disease. 2018;41(2):209-19. doi: 10.1007/s10545-017-0098-3.

9. Wasserstein MP, Caggana M, Bailey SM, Desnick RJ, Edelmann L, Estrella L, et al. The New York pilot newborn screening program for lysosomal storage diseases: Report of the First 65,000 Infants. Genetics in Medicine. 2019;21(3):631-40. doi: 10.1038/s41436-018-0129-y. 
10. Ellaway C. Diagnostic dilemma and delay in Fabry disease: Insights from a case series of young female patients. Journal of Paediatrics and Child Health. 2014;51(4):n/a-n/a. doi: 10.1111/jpc.12732.

11. Liao HC, Huang YH, Chen YJ, Kao SM, Lin HY, Huang CK, et al. Plasma globotriaosylsphingosine (lysoGb3) could be a biomarker for Fabry disease with a Chinese hotspot late-onset mutation (IVS4+919G>A). Clinica Chimica Acta. 2013;426:114-20. doi: 10.1016/j.cca.2013.09.008.

12. Feriozzi S, Hughes DA. New drugs for the treatment of Anderson-Fabry disease: Springer; 2020.

13. Concolino D, Degennaro E, Parini R, Antuzzi D, Bembi B, Benso A, et al. Delphi consensus on the current clinical and therapeutic knowledge on Anderson-Fabry disease. European Journal of Internal Medicine. 2014;25(8):751-6. doi: 10.1016/j.ejim.2014.07.009. 14. Smid BE, Van Der Tol L, Cecchi F, Elliott PM, Hughes DA, Linthorst GE, et al. Uncertain diagnosis of Fabry disease: Consensus recommendation on diagnosis in adults with left ventricular hypertrophy and genetic variants of unknown significance. International Journal of Cardiology. 2014;177(2):400-8. doi: 10.1016/j.ijcard.2014.09.001.

15. van der Tol L, Cassiman D, Houge G, Janssen MC, Lachmann RH, Linthorst GE, et al. Uncertain diagnosis of fabry disease in patients with neuropathic pain, angiokeratoma or cornea verticillata: Consensus on the approach to diagnosis and follow-up. 17: Springer; 2014. p. 83-90.

16. van der Tol L, Svarstad E, Ortiz A, Tøndel C, Oliveira JP, Vogt L, et al. Chronic kidney disease and an uncertain diagnosis of Fabry disease: Approach to a correct diagnosis. Molecular Genetics and Metabolism. 2015;114(2):242-7. doi: 10.1016/j.ymgme.2014.08.007. 17. FDA. Fabry Disease: Developing Drugs for Treatment Guidance for Industry.

18. lii EPC. The Optimal Number of Response Alternatives for a Scale: A Review. Journal of Marketing Research. 1980;17(4):407-. doi: 10.2307/3150495.

19. A Study of Two Fabrazyme (Agalsidase Beta) Dosing Regimens in Treatment-naïve, Male Pediatric Patients Without Severe Symptoms. Available from: https://ClinicalTrials.gov/show/NCT00701415.

20. Efficacy and Safety of Lucerastat Oral Monotherapy in Adult Subjects With Fabry Disease. Available from: https://ClinicalTrials.gov/show/NCT03425539.

21. Eng CM, Guffon N, Wilcox WR, Germain DP, Lee P, Waldek S, et al. Safety and efficacy of recombinant human $\alpha$-galactosidase a replacement therapy in Fabry's disease. New England Journal of Medicine. 2001;345(1):9-16. doi: 10.1056/NEJM200107053450102.

22. Germain DP, Hughes DA, Nicholls K, Bichet DG, Giugliani R, Wilcox WR, et al. Treatment of Fabry's Disease with the Pharmacologic Chaperone Migalastat. New England Journal of Medicine. 2016;375(6):545-55. doi: 10.1056/NEJMoa1510198.

23. Schiffmann R, Kopp JB, Austin HA, Sabnis S, Moore DF, Weibel T, et al. Enzyme replacement therapy in fabry disease a randomized controlled trial. Journal of the American Medical Association. 2001;285(21):2743-9. doi: 10.1001/jama.285.21.2743.

24. Thurberg BL, Byers HR, Granter SR, Phelps RG, Gordon RE, O'Callaghan M. Monitoring the 3-year efficacy of enzyme replacement therapy in fabry disease by repeated skin biopsies. Journal of Investigative Dermatology. 2004;122(4):900-8. doi: 10.1111/j.0022-

202X.2004.22425.x.

25. Hughes DA, Elliott PM, Shah J, Zuckerman J, Coghlan G, Brookes J, et al. Effects of enzyme replacement therapy on the cardiomyopathy of Anderson-Fabry disease: $\mathrm{A}$ randomised, double-blind, placebo-controlled clinical trial of agalsidase alfa. Heart. 2008;94(2):153-8. doi: 10.1136/hrt.2006.104026.

26. Hughes DA, Nicholls K, Shankar SP, Sunder-Plassmann G, Koeller D, Nedd K, et al. Oral pharmacological chaperone migalastat compared with enzyme replacement therapy in Fabry disease: 18-month results from the randomised phase III ATTRACT study. Journal of Medical Genetics. 2017;54(4):288-96. doi: 10.1136/jmedgenet-2016-104178. 
27. Banikazemi M, Bultas J, Waldek S, Wilcox WR, Whitley CB, McDonald M, et al. Agalsidase-beta therapy for advanced fabry disease: A randomized trial. Annals of Internal Medicine. 2007;146(2):77-86. doi: 10.7326/0003-4819-146-2-200701160-00148.

28. Hajioff D, Enever Y, Quiney R, Zuckerman J, Mackermot K, Mehta A. Hearing loss in Fabry disease: The effect of agalsidase alfa replacement therapy. Journal of Inherited Metabolic Disease. 2003;26(8):787-94. doi: 10.1023/B:BOLI.0000009948.86528.72.

29. Moore DF, Altarescu G, Herscovitch P, Schiffmann R. Enzyme replacement reverses abnormal cerebrovascular responses in Fabry disease. BMC Neurology. 2002;2. doi: 10.1186/1471-2377-2-4.

30. Moore DF, Altarescu G, Ling GSF, Jeffries N, Frei KP, Weibel T, et al. Elevated cerebral blood flow velocities in Fabry disease with reversal after enzyme replacement. Stroke. 2002;33(2):525-31. doi: 10.1161/hs0202.102601.

31. Schiffmann R, Hauer P, Freeman B, Ries M, Scott LC, Polydefkis M, et al. Enzyme replacement therapy and intraepidermal innervation density in Fabry disease. Muscle and Nerve. 2006;34(1):53-6. doi: 10.1002/mus.20550.

32. Study of the Safety and Efficacy of PRX-102 Compared to Agalsidase Beta on Renal Function. Available from: https://ClinicalTrials.gov/show/NCT02795676.

33. Bierer G, Balfe D, Wilcox WR, Mosenifar Z. Improvement in serial cardiopulmonary exercise testing following enzyme replacement therapy in Fabry disease. Journal of Inherited Metabolic Disease. 2006;29(4):572-9. doi: 10.1007/s10545-006-0361-5.

34. Study to Evaluate the Safety and Efflcacy of PRX-102 on Gastrointestinal Symptoms in Naïve Fabry Disease. Available from: https://ClinicalTrials.gov/show/NCT02921620.

35. Moore DF, Scott LTC, Gladwin MT, Altarescu G, Kaneski C, Suzuki K, et al. Regional cerebral hyperperfusion and nitric oxide pathway dysregulation in fabry disease: Reversal by enzyme replacement therapy. Circulation. 2001;104(13):1506-12. doi:

10.1161/hc3801.096352.

36. Kempf L, Goldsmith JC, Temple R. Challenges of developing and conducting clinical trials in rare disorders: Wiley-Liss Inc.; 2018 [cited 176]. 773-83].

37. Logviss K, Krievins D, Purvina S. Characteristics of clinical trials in rare vs. common diseases: A register-based Latvian study. PLoS ONE. 2018;13(4). doi:

10.1371/journal.pone.0194494.

38. Bothwell LE, Avorn J, Khan NF, Kesselheim AS. Adaptive design clinical trials: A review of the literature and ClinicalTrials.gov. BMJ Open. 2018;8(2). doi: 10.1136/bmjopen-2017018320.

39. Chow S-C. Adaptive Clinical Trial Design. Annual Review of Medicine. 2014;65(1):40515. doi: 10.1146/annurev-med-092012-112310.

40. Hilz MJ, Kolodny EH, Brys M, Stemper B, Haendl T, Marthol H. Reduced cerebral blood flow velocity and impaired cerebral autoregulation in patients with Fabry disease. Journal of Neurology. 2004;251(5):564-70. doi: 10.1007/s00415-004-0364-9.

41. Kolodny E, Fellgiebel A, Hilz MJ, Sims K, Caruso P, Phan TG, et al. Cerebrovascular involvement in Fabry disease: current status of knowledge. Stroke. 2015;46(1):302-13. Epub 2014/12/11. doi: 10.1161/STROKEAHA.114.006283. PubMed PMID: 25492902.

42. Loeb J, Feldt-Rasmussen U, Madsen CV, Vogel A. Cognitive Impairments and Subjective Cognitive Complaints in Fabry Disease: A Nationwide Study and Review of the Literature. JIMD Rep. 2018;41:73-80. Epub 2018/04/15. doi: 10.1007/8904_2018_103. PubMed PMID:

29654545; PubMed Central PMCID: PMCPMC6122045.

43. Rolfs A, Bottcher $T$, Zschiesche M, Morris $P$, Winchester B, Bauer $P$, et al. Prevalence of Fabry disease in patients with cryptogenic stroke: a prospective study. Lancet.

2005;366(9499):1794-6. Epub 2005/11/22. doi: 10.1016/S0140-6736(05)67635-0. PubMed PMID: 16298216.

44. Rolfs A, Fazekas F, Grittner U, Dichgans M, Martus P, Holzhausen M, et al. Acute cerebrovascular disease in the young: the Stroke in Young Fabry Patients study. Stroke. 
2013;44(2):340-9. Epub 2013/01/12. doi: 10.1161/STROKEAHA.112.663708. PubMed PMID: 23306324.

45. Skrunes R, Tøndel C, Leh S, Larsen KK, Houge G, Davidsen ES, et al. Long-term dosedependent agalsidase effects on kidney histology in fabry disease. Clinical Journal of the American Society of Nephrology. 2017;12(9):1470-9. doi: 10.2215/CJN.01820217.

46. Lee TH, Yang JT, Lee JD, Chang KC, Peng TI, Chang TY, et al. Genomic screening of Fabry disease in young stroke patients: the Taiwan experience and a review of the literature. European Journal of Neurology. 2019;26(3):553-5. doi: 10.1111/ene.13775.

47. Körver S, Vergouwe M, Hollak CEM, van Schaik IN, Langeveld M. Development and clinical consequences of white matter lesions in Fabry disease: a systematic review: Academic Press Inc.; 2018 [cited 125]. 205-16]. Available from:

https://pubmed.ncbi.nlm.nih.gov/30213639/.

48. Körver S, Longo MGF, Lima MR, Hollak CEM, El Sayed M, Van Schaik IN, et al. Determinants of cerebral radiological progression in Fabry disease. Journal of Neurology, Neurosurgery and Psychiatry. 2020;91(7):756-63. doi: 10.1136/jnnp-2019-322268.

49. Sado DM, White SK, Piechnik SK, Banypersad SM, Treibel T, Captur G, et al. Identification and assessment of anderson-fabry disease by cardiovascular magnetic resonance noncontrast myocardial T1 mapping. Circulation: Cardiovascular Imaging. 2013;6(3):392-8. doi: 10.1161/CIRCIMAGING.112.000070.

50. Messroghli DR, Moon JC, Ferreira VM, Grosse-Wortmann L, He T, Kellman P, et al. Clinical recommendations for cardiovascular magnetic resonance mapping of $\mathrm{T} 1, \mathrm{~T} 2, \mathrm{~T} 2$ and extracellular volume: A consensus statement by the Society for Cardiovascular Magnetic Resonance (SCMR) endorsed by the European Association for Cardiovascular Imaging (EACVI): BioMed Central Ltd.; 2017 [cited 19].

51. Weidemann F, Maier SK, Stork S, Brunner T, Liu D, Hu K, et al. Usefulness of an Implantable Loop Recorder to Detect Clinically Relevant Arrhythmias in Patients With Advanced Fabry Cardiomyopathy. Am J Cardiol. 2016;118(2):264-74. Epub 2016/06/07. doi: 10.1016/j.amjcard.2016.04.033. PubMed PMID: 27265676.

52. Arrhythmia Burden, Risk of Sudden Cardiac Death and Stroke in Patients With Fabry Disease. Available from: https://ClinicalTrials.gov/show/NCT03305250.

53. Riccio E, Sabbatini M, Capuano I, Pisani A. Early Biomarkers of Fabry Nephropathy: A Review of the Literature: S. Karger AG; 2019 [cited 143]. 274-81]. Available from: https://pubmed.ncbi.nlm.nih.gov/31614349/.

54. Tøndel C, Kanai T, Larsen KK, Ito S, Politei JM, Warnock DG, et al. Foot Process Effacement Is an Early Marker of Nephropathy in Young Classic Fabry Patients without Albuminuria. Nephron. 2015;129(1):16-21. doi: 10.1159/000369309.

55. Thofehrn S, Netto C, Cecchin C, Burin M, Matte U, Brustolin S, et al. Kidney function and 24-hour proteinuria in patients with fabry disease during 36 months of agalsidase alfa enzyme replacement therapy: A brazilian experience. Renal Failure. 2009;31(9):773-8. doi: 10.3109/08860220903150296.

56. FDA. Guidance for Industry Patient-Reported Outcome Measures: Use in Medical Product Development to Support Labeling Claim. Available from:

https://www.fda.gov/regulatory-information/search-fda-guidance-documents/patientreported-outcome-measures-use-medical-product-development-support-labeling-claims.

57. Zar-Kessler C, Karaa A, Sims KB, Clarke V, Kuo B. Understanding the gastrointestinal manifestations of Fabry disease: Promoting prompt diagnosis: SAGE Publications Ltd; 2016 [cited 9]. 626-34].

58. Biegstraaten M, Arngrímsson R, Barbey F, Boks L, Cecchi F, Deegan PB, et al. Recommendations for initiation and cessation of enzyme replacement therapy in patients with Fabry disease: The European Fabry Working Group consensus document. Orphanet Journal of Rare Diseases. 2015;10(1). doi: 10.1186/s13023-015-0253-6. 
59. Politei JM, Bouhassira D, Germain DP, Goizet C, Guerrero-Sola A, Hilz MJ, et al. Pain in Fabry Disease: Practical Recommendations for Diagnosis and Treatment. CNS Neuroscience and Therapeutics. 2016;22(7):568-76. doi: 10.1111/cns.12542.

60. Nowak A, Mechtler TP, Desnick RJ, Kasper DC. Plasma LysoGb3: A useful biomarker for the diagnosis and treatment of Fabry disease heterozygotes. Molecular Genetics and Metabolism. 2017;120(1-2):57-61. doi: 10.1016/j.ymgme.2016.10.006.

61. Nowak A, Mechtler TP, Hornemann T, Gawinecka J, Theswet E, Hilz MJ, et al.

Genotype, phenotype and disease severity reflected by serum LysoGb3 levels in patients with Fabry disease. Molecular Genetics and Metabolism. 2018;123(2):148-53. doi:

10.1016/j.ymgme.2017.07.002.

62. Effraimidis $\mathrm{G}$, Feldt-Rasmussen $\mathrm{U}$, Rasmussen ÅK, Lavoie $\mathrm{P}$, Abaoui $\mathrm{M}$, Boutin $\mathrm{M}$, et al. Globotriaosylsphingosine (lyso-Gb 3 ) and analogues in plasma and urine of patients with Fabry disease and correlations with long-term treatment and genotypes in a nationwide female Danish cohort. Journal of Medical Genetics. 2020:jmedgenet-2020-107162. doi:

10.1136/jmedgenet-2020-107162. 